\section{Biometry of the silicone oil-filled eye: \\ II}

Abstract

Purpose In phakic silicone oil-filled eyes, removal of the silicone oil can be combined with phacoemulsification and intraocular lens (IOL) implantation. True axial length (AL) of the silicone oil-filled (viscosity 1300 centistokes) eye can be estimated from the measured AL (MAL) obtained on A and/or B scan echography, by multiplying MAL by a conversion factor of $\mathbf{0 . 7 1}$. IOL power can then be calculated using current biometry formulae (SRK/T). This study aims to evaluate the conversion factor in clinical practice.

Methods Eleven patients undergoing combined removal of silicone oil and phacoemulsification with IOL implant were studied. Patients were divided into two groups. In Group 1 (seven patients), the IOL was placed in the capsular bag and in Group 2 (four patients) the IOL was placed in the ciliary sulcus. Calculated AL (CAL) was obtained by multiplying the MAL of the silicone oil-filled eye (as measured on A or B scan ultrasonagraphy) by the conversion factor of 0.71 . IOL power was then estimated using the CAL in the SRK/T formula. The spherical equivalent of the postoperative refractive error was compared to predicted refractive error.

Results The mean difference in actual and predicted refractive error was 0.74 dioptres (D) (standard deviation 0.75 D) for Group 1 and 1.31 D (standard deviation 1.4 D) for Group 2.

Conclusions The conversion factor of 0.71 corrects for the apparent increase in $\mathrm{AL}$ induced by silicone oil of viscosity 1300 centistokes. This allows accurate prediction of the required IOL power in eyes undergoing combined cataract extraction, removal of silicone oil and lens implant. Sulcus placement of the IOL gives a less predictable result than placement in the capsular bag.
DC Murray, OM Durrani, P Good, MT Benson and GR Kirkby

Eye (2002) 16, 727-730. doi:10.1038/

sj.eye. 6700176

Keywords: silicone oil; axial length; biometry; conversion factor

\section{Introduction}

Cataracts frequently form after the use of silicone oil as a tamponade agent in vitreoretinal surgery. ${ }^{1-7}$ In some patients, removal of silicone oil can be combined with phacoemulsification of the cataract and intraocular lens (IOL) implantation. ${ }^{1,2}$ thus avoiding subsequent surgery. Accurate determination of IOL power can present a dilemma since the true axial length $(\mathrm{AL})$ of the eye is often unknown, and the echographically measured AL (MAL) of the silicone oil-filled eye is greater than the true AL. ${ }^{8-10}$ We have previously established a conversion factor of 0.71 which allows estimation of the true AL from the MAL so that desired IOL power can be accurately estimated despite the presence of silicone oil. ${ }^{8}$ Whilst most biometry machines allow a conversion of the speed of sound through vitreous to 987 metres/second, the absorption of sound waves through the silicone oil and the resultant loss of sensitivity often makes it impossible to get an accurate A-scan. The object of this study was to test the accuracy of our conversion factor in clinical practice.

\section{Materials and methods}

Eleven phakic eyes with silicone oil (Oxane ${ }^{\circledR}$, Chauvin, France; viscosity 1300 centistokes) in the posterior segment were studied. Nine eyes had undergone successful retinal reattachment surgery (five for rhegmatogenous retinal detachment and four with traction retinal detachment complicating proliferative diabetic retinopathy), and two eyes had undergone macular hole surgery. All eyes had
Birmingham \& Midland Eye Centre

City Hospital NHS Trust Birmingham, UK

Correspondence:

O Durrani

Birmingham and Midland Eye Centre

City Hospital NHS Trust Dudley Road Birmingham B18 7QU, UK Fax: +44 (0) 1215076853 E-mail: o.durrani@ bham.ac.uk

Received: 1 August 2001 Accepted: 12 February 2002 
subsequently developed visually significant lens opacity. MALs were obtained, using A-mode echography (10 MHz central frequency, Quantel BVI AXIS biometry apparatus). With the patient in the upright position, the transducer was oriented so that the ultrasound beam was perpendicular to the globe. B-mode echography was also performed to ensure that the MAL measurement obtained with the A-scan was accurate and that the retinal spike seen was not an artefact. The MAL was multiplied by the conversion factor of 0.71 in order to estimate the CAL of the eye. The CAL was then inserted into the SRK/T biometry formula, and IOL power for the desired postoperative refraction determined. Refraction was carried out using manual retinoscopy in all patients.

\section{Surgical technique}

All patients had combined removal of silicone oil, phacoemulsification and intraocular lens implant. The IOL was then implanted into either the capsular bagGroup 1 (seven patients) or the ciliary sulcus-Group 2 (four patients). A variety of foldable IOLs were used (Table 1), including Rayner rigid polymethylmethacrylate (PMMA) (one patient), Alcon Acrysof soft acrylic (four patients), Storz Hydroview (five patients), and Allergan SI40 silicone (one patient). The corresponding A constant for each IOL was employed in the SRK/T biometry formula. ${ }^{11}$

\section{Results \\ Measured axial length (MAL) and calculated axial length (CAL) (Table 2)}

MAL ranged from $29.76 \mathrm{~mm}$ to $40.49 \mathrm{~mm}$ (mean $34.02 \mathrm{~mm})$. CAL $(\mathrm{MAL} \times 0.71)$ ranged from $21.13 \mathrm{~mm}$ to $28.75 \mathrm{~mm}$ (mean $24.15 \mathrm{~mm}$ ).

\section{Time between combined cataract surgery and removal of silicone oil and refraction}

The time between removal of silicone oil and refraction ranged from 2 weeks to 25 weeks (mean 8.27 weeks).

\section{Predicted and actual postoperative refraction (spherical equivalent)-(Table 1)}

Desired postoperative refraction ranged from $+0.31 \mathrm{D}$ to $-5.84 \mathrm{D}$ and actual postoperative refraction ranged from $+1.00 \mathrm{D}$ to $-9.0 \mathrm{D}$. The difference between the suggested target and actual postoperative refraction ranged from 0 dioptres to $1.83 \mathrm{D}$ (mean $0.74 \mathrm{D}, \mathrm{SD}$
Table 1 Predicted and actual refraction after combined removal of silicone oil, phacoemulsification and intraocular lens implantation

\begin{tabular}{|c|c|c|c|c|c|}
\hline \multirow[t]{2}{*}{ Placement } & \multicolumn{3}{|c|}{ Refraction $^{a}(D)$} & \multirow[t]{2}{*}{ IOL design } & \multirow[t]{2}{*}{$I O L$} \\
\hline & Predicted & Actual & Difference & & \\
\hline \multicolumn{6}{|l|}{ Group 1} \\
\hline 1 & -0.06 & +0.5 & 0.56 & $\begin{array}{l}\text { Rayner } \\
\mathrm{A}=118.0\end{array}$ & Bag \\
\hline 2 & -0.17 & -2.00 & 1.83 & $\begin{array}{l}\text { Storz } \\
\text { Hydroview } \\
\mathrm{A}=118.3\end{array}$ & Bag \\
\hline 3 & -1.90 & -1.90 & 0.00 & $\begin{array}{l}\text { Storz } \\
\text { Hydroview } \\
\mathrm{A}=118.3\end{array}$ & Bag \\
\hline 4 & +0.16 & +0.50 & 0.34 & $\begin{array}{l}\text { Storz } \\
\text { Hydroview } \\
\mathrm{A}=118.3\end{array}$ & Bag \\
\hline 5 & +0.31 & +0.50 & 0.19 & $\begin{array}{l}\text { Storz } \\
\text { Hydroview } \\
\mathrm{A}=118.3\end{array}$ & Bag \\
\hline 6 & 0.00 & -0.50 & 0.50 & $\begin{array}{l}\text { Storz } \\
\text { Hydroview } \\
\mathrm{A}=118.3\end{array}$ & Bag \\
\hline 7 & -0.76 & +1.00 & 1.76 & $\begin{array}{l}\text { Allergan } \\
\text { SI40 } \\
\mathrm{A}=117.4\end{array}$ & Bag \\
\hline \multicolumn{6}{|c|}{ Difference in actual and predicted refraction } \\
\hline Mean & & & 0.74 & & \\
\hline Median & & & 0.5 & & \\
\hline Standarc & d deviation & & 0.75 & & \\
\hline \multicolumn{6}{|l|}{ Group 2} \\
\hline 1 & -1.00 & -2.75 & 1.75 & $\begin{array}{l}\text { Acrysof } \\
A=118.9\end{array}$ & Sulcus \\
\hline 2 & -2.85 & -2.75 & 0.10 & $\begin{array}{l}\text { Acrysof } \\
A=118.9\end{array}$ & Sulcus \\
\hline 3 & -5.84 & -9.00 & 3.16 & $\begin{array}{l}\text { Acrysof } \\
A=118.9\end{array}$ & Sulcus \\
\hline 4 & +0.28 & +0.50 & 0.22 & $\begin{array}{l}\text { Acrysof } \\
A=118.9\end{array}$ & Sulcus \\
\hline \multicolumn{6}{|c|}{ Difference in actual and predicted refraction } \\
\hline Mean & & & 1.3 & & \\
\hline Median & & & 0.98 & & \\
\hline Standare & d deviation & & 1.44 & & \\
\hline
\end{tabular}

$0.5 \mathrm{D}$ ) in Group 1, and 0.10 D to 3.16 D (mean 1.31 D, SD 0.98 D) in Group 2.

\section{Discussion}

Long-term complications including cataract, raised intraocular pressure, and band keratopathy, frequently occur after the use of silicone oil. ${ }^{1-7}$ One study showed that after one year, 30 out of 61 eyes (49\%) exhibited some degree of clinically recognisable lens changes, which were not present before surgery. ${ }^{6}$ The incidence 
Table 2 Measured axial length (MAL) and calculated axial length (CAL) in 11 phakic silicone oil-filled ${ }^{a}$ eyes

\begin{tabular}{ccc}
\hline Patient No. & $\begin{array}{c}\text { Measured } A L(M A L) \\
(\mathrm{mm})\end{array}$ & $\begin{array}{c}\text { Calculated } A L \\
(\mathrm{CAL})=M A L \times 0.71 \\
(\mathrm{~mm})\end{array}$ \\
\hline 1 & 33.29 & 23.64 \\
2 & 33.63 & 23.88 \\
3 & 30.56 & 21.70 \\
4 & 35.77 & 25.40 \\
5 & 32.75 & 23.25 \\
6 & 29.76 & 21.13 \\
7 & 33.30 & 23.64 \\
8 & 37.17 & 26.39 \\
9 & 32.01 & 22.73 \\
10 & 40.49 & 28.75 \\
11 & 35.46 & 25.18 \\
\hline
\end{tabular}

aViscosity 1300 centistokes.

of this finding rose to $74 \%$ of 35 eyes assessed at 2 years. Another study showed that eyes that had undergone vitrectomy with silicone oil for severe proliferative diabetic retinopathy (PDR) had the least progression of PDR and the best prognosis for visual acuity when the silicone oil was removed, the cataract extracted and an IOL implanted at the same operation. $^{12}$

Removal of silicone oil is therefore the preferred option, since the incidence of complications, causing sometimes irreversible deterioration of vision is reduced. Using the combined technique of cataract extraction, silicone oil removal and lens implantation, patients are often spared the burden of more than one operation.

At present, deciding the power of IOL to be used in eyes undergoing this combined technique poses a dilemma. Some advocate measuring the AL prior to every vitrectomy, but the AL may be different after surgery especially if encircling explants are used and measuring the AL accurately in eyes with extensive RD may be difficult. If pre-operative biometry is not done, then IOL power calculation is dependent on the usual parameters, namely the desired postoperative refractive error, the anterior chamber depth factor, the average corneal power, and most significantly, the AL of the eye. ${ }^{13}$ The presence of silicone oil renders the determination of AL difficult. AL measurements obtained from the contra-lateral eye or the AL of an average eye are therefore often used, but there are also limitations with these methods. In eyes that have silicone oil as a tamponade agent, there is an apparent increase in AL, as measured by echography. ${ }^{8-10}$ This is because the velocity of sound in silicone oil is slower than in vitreous humour, being $987 \mathrm{~m} / \mathrm{s}$ in silicone oil of viscosity 1000 centistokes, compared to $1532 \mathrm{~m} / \mathrm{s}$ in aqueous and vitreous. ${ }^{13}$ When the vitreous humour is replaced with silicone oil, it takes approximately 1.5 times as long for an ultrasound pulse to traverse the vitreous cavity. ${ }^{10}$ The depth of the vitreous cavity is therefore overestimated if allowance is not made for the accompanying reduction in the velocity of sound (Distance $=$ velocity $\times$ time $)$.

Whilst most biometry machines allow a conversion of the speed of sound through vitreous to $987 \mathrm{~m} / \mathrm{s}$, the absorption of sound waves through the silicone oil and the resultant loss of sensitivity often makes it impossible to get an accurate A-scan. In addition, the velocity of sound varies with the viscosity of the silicone oil, becoming increasingly slower as the viscosity increases. The viscosity of the silicone oil used in this study was 1300 centistokes. Sound velocity through this more viscous oil would therefore be less than through oil of viscosity 1000 centistokes, but the exact velocity is unknown. The conversion factor of 0.71 was determined in our previous study using silicone oil of viscosity 1300 centistokes. ${ }^{8}$ It was here used to estimate true AL from the MAL of 11 silicone oil-filled eyes.

This study has shown that it is possible to calculate the true AL in eyes with silicone oil by using a conversion factor of 0.71 . This can minimise postoperative refractive errors resulting from inaccurate IOL power calculation (Table 1). In group 1, where IOL was placed in the bag, $5 / 7$ eyes (71.4\%) were within $0.56 \mathrm{D}$ of predicted refraction. The median difference between predicted and actual refraction was only $0.5 \mathrm{D}$ for this group. As expected this study also shows that sulcus placement of the IOL gives a less predictable result than placement in the capsular bag: the median difference between predicted and actual refraction in group 2 was 0.98 D. Patient 3, in group 2, had the largest difference between the predicted and actual refraction $(3.16 \mathrm{D})$. The patient is a myope with an axial length of $28.75 \mathrm{~mm}$ and this factor may have contributed to the inaccurate biometry in this patient. Some authorities say that if an eye requires the use of silicone oil, the accuracy of biometry does not matter due to poor visual prognosis. This may be true in eyes with advanced PVR, but often silicone oil is used because of problems with patients posturing following procedures like macular hole repair. Therefore this is not a completely valid criticism. This conversion factor can only be used for silicone oil of viscosity 1300 centistokes. Oils of different viscosity will have a different constant, which can be determined as previously described. ${ }^{8}$ 


\section{Acknowledgements}

Findings from this study were presented as a poster at The Royal College of Ophthalmologists Congress 2001.

\section{References}

1 Jonas JB, Budde WM, Panda-Jonas S. Cataract surgery combined with transpupillary silicone oil removal through planned posterior capsulotomy. Ophthalmology 1998; 105: 1234-1238.

2 Baer RM, Aylward WG, Leaver PK. Cataract extraction following vitrectomy and silicone oil tamponade. Eye 1995; 9: 309-312.

3 Gonvers M. Temporary silicone oil tamponade in the management of retinal detachment with proliferative vitreo-retinopathy. Am J Ophthalmol 1985; 100: 239-245.

4 McCartney DL, Miller KM, Stark WJ, Guyton DL, Michels RG. Intraocular lens style and refraction in eyes treated with silicone oil. Arch Opthhalmol 1987; 105: 1385-1387.

5 Grey RHB, Leaver PK. Silicone oil in treatment of massive preretinal retraction. Results in 105 eyes. $\mathrm{Br} \mathrm{J}$ Ophthalmol 1979; 63: 355-360.

6 Leaver PK, Grey RHB, Garner A. Silicone oil injection in the treatment of massive preretinal retraction. II. Late complications in 93 eyes. Br J Ophthalmol 1979; 63: 361367.

7 Grinbaum A, Treister G, Moisseiev J. Predicted and actual refraction after intraocular lens implantation in eye with silicone oil. J Cataract Refract Surg 1996; 22: 726-729.

8 Murray DC, Potamitis T, Good P, Kirkby GR, Benson MT. Biometry of the silicone oil-filled eye. Eye 1999; 13: 319-324.

9 Clemens S, Kroll P, Rochels R. Ultrasonic findings after treatment of retinal detachment by intravitreal silicone instillation. Am J Ophthalmol 1984; 98: 369-373.

10 Shugar JK, deJuan E Jr, McCuen BW II, Tiedeman J, Landers MR III, Machemer R. Ultrasonic examination of the silicone-filled eye: theoretical and practical considerations. Graefe's Arch Clin Exp Ophthalmol 1986; 224: 361-367.

11 Retzlaff JA, Sanders DR, Kraff MC. Development of the SRK/T intraocular lens power calculation formula. J Cataract Refract Surg 1990; 16: 333-340.

12 Sugai H, Nakano H, Himiya A, Koshiba R, Funatsu H, Hori S. Results of intraocular lens implantation associated with injection and removal of silicone oil. Folia Ophthalmologica Japonica 1996; 47: 237-242.

13 Hoffer KJ. Ultrasound velocities for axial eye length measurement. J Cataract Refract Surg 1994; 20: 554-562. 